\title{
Anti-apoptogenic function of TGF $\beta 1$ for human synovial cells: TGF $\beta 1$ protects cultured synovial cells from mitochondrial perturbation induced by several apoptogenic stimuli
}

\author{
A Kawakami, S Urayama, S Yamasaki, A Hida, T Miyashita, M Kamachi, K Nakashima, \\ F Tanaka, H Ida, Y Kawabe, T Aoyagi, I Furuichi, K Migita, T Origuchi, K Eguchi
}

Ann Rheum Dis 2004;63:95-97. doi: 10.1136/ard.2003.014159

\begin{abstract}
Objective: To investigate anti-apoptogenic mechanism of transforming growth factor $\beta 1$ (TGF $\beta 1$ ) towards synovial cells.

Methods: Isolated synovial cells, treated or not with TGF $\beta 1$, were cultured in the presence or absence of anti-Fas IgM, proteasome inhibitor Z-Leu-Leu-Leu-aldehyde (LLL-CHO), etoposide, or C2-ceramide. After cultivation, apoptosis of synovial cells was examined by the presence of hypodiploid DNA $^{+}$cells, the presence of terminal deoxy (d)-UTP nick end labelling ${ }^{+}$cells (TUNEL ${ }^{+}$cells), activation of caspases, and disruption of mitochondrial transmembrane potential $(\Delta \Psi \mathrm{m})$. Results: Activation of caspase- 9 and $\Delta \Psi \mathrm{m}$ was found in antiFas IgM treated synovial cells. The increment of both hypodiploid $\mathrm{DNA}^{+}$cells and $\mathrm{TUNEL}^{+}$cells accompanied by the activation of caspase- 8 and caspase- 3 was also determined in anti-Fas IgM treated synovial cells. These hallmarks for apoptosis induced by anti-Fas $\lg M$ were significantly suppressed in TGF $\beta 1$ treated synovial cells. LLL-CHO, etoposide, and C2-ceramide also caused $\Delta \Psi \mathrm{m}$, the increment of both hypodiploid DNA ${ }^{+}$cells and $\mathrm{TUNEL}^{+}$ cells, and the activation of both Leu-Glu-His-Asp ase (LEHDase; caspase-9 like activity) and Asp-Glu-Val-Asp ase (DEVDase; caspase-3 like activity) in synovial cells. As determined in anti-Fas IgM treatment, TGF $\beta 1$ significantly reduced apoptotic cell death of synovial cells induced by the above chemicals.

Conclusions: The protective effect of TGF $\beta 1$ for mitochondrial homoeostasis may be important in the anti-apoptogenic function of TGF $\beta 1$ for synovial cells.
\end{abstract}

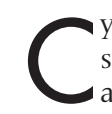
ytokines and growth factors present in rheumatoid synovial tissues are important factors which regulate an apoptotic process of synovial cells. ${ }^{1-5}$ Transforming growth factor $\beta 1$ (TGF $\beta 1$ ) is highly expressed in rheumatoid synovial tissues, ${ }^{6}$ and found to possess an anti-apoptogenic effect for synovial cells; this was demonstrated by the experimental results showing that TGF $\beta 1$ inhibits Fas mediated apoptosis as well as proteasome inhibitor induced apoptosis in cultured synovial cells. ${ }^{2}$ TGF $\beta 1$ not only suppresses Fas expression, but increases the expression of Bcl-2 and Bcl-xL in cultured synovial cells. ${ }^{23}$ the latter finding implies that TGF $\beta 1$ protects synovial cells from apoptogenic stimuli through a mitochondria dependent mechanism.

We show in this study that mitochondrial perturbation as well as both DNA fragmentation and the activation of caspases in cultured synovial cells, induced by several apoptogenic stimuli, are significantly suppressed by TGF $\beta 1$ treatment, which may be closely associated with the antiapoptogenic function of TGF $\beta 1$.

\section{MATERIALS AND METHODS \\ Synovial cell culture}

Synovial cells were isolated from synovial tissues obtained from 18 patients with rheumatoid arthritis (RA) who met the American College of Rheumatology criteria for $\mathrm{RA}^{7}$ at the time of orthopaedic surgery, as we previously described..$^{2-5}$ In some experiments, synovial cells isolated from patients with osteoarthritis were also used in this study. The adherent synovial cells used in this study at third to fifth passages were less than $1 \%$ reactive with monoclonal antibodies, including CD3, CD68, CD20, and von Willebrand factor, which are defined as fibroblast-like synovial cells.

\section{Induction of synovial cell apoptosis by several apoptogenic stimuli}

Synovial cells were cultured with or without recombinant human TGF $\beta 1$ ( $5 \mathrm{ng} / \mathrm{ml}$; R\&D Systems Inc, Minneapolis, MN) for 48 hours in RPMI 1640 containing 2\% bovine serum albumin. After incubation, apoptosis sensitivity in untreated or TGF $\beta 1$ treated synovial cells was examined by further incubation with anti-Fas IgM $(1 \mu \mathrm{g} / \mathrm{ml}$ for 12 hours; MBL, Nagoya, Japan), Z-Leu-Leu-Leu-aldehyde (LLL-CHO, $10 \mu \mathrm{M}$ for 24 hours, Peptide Institute, Osaka, Japan), etoposide ( $50 \mu \mathrm{M}$ for 24 hours; TopoGen, Inc, Columbus, Ohio), or C2ceramide ( $50 \mu \mathrm{M}$ for 24 hours; Sigma). Apoptosis of synovial cells was quantified by the presence of hypodiploid $\mathrm{DNA}^{+}$ cells, the presence of terminal deoxy (d)-UTP nick end labelling ${ }^{+}$cells (TUNEL ${ }^{+}$cells), activation of caspases, and disruption of mitochondrial transmembrane potential $(\Delta \Psi \mathrm{m})$ as previously described. ${ }^{3} 589$

DNA fragmentation was estimated by the presence of hypodiploid $\mathrm{DNA}^{+}$cells and $\mathrm{TUNEL}^{+}$cells, determined by flow cytometry (Epics XL, Beckman Coulter, Hialeah, FL). Detection of hypodiploid $\mathrm{DNA}^{+}$cells was done by propidium iodide staining $(100 \mu \mathrm{g} / \mathrm{ml}$; Sigma Chemical Co, St Louis, MO), and TUNEL was examined by Mebstain Apoptosis Kit (MBL, Nagoya, Japan).

Activation of caspases in synovial cells was studied by western blot analysis, colorimetric protease assay and flow cytometry. Western blot analysis was done by

Abbreviations: DEVDase, Asp-Glu-Val-Asp ase; DiOC6, 3, 3'dihexyloxacarbocyamine iodide; $\Delta \psi \mathrm{m}$, disruption of mitochondrial transmembrane potential; IETDase, lle-Glu-Thr-Asp ase; LEHDase, LeuGlu-His-Asp ase; LLL-CHO, Z-Leu-Leu-Leu-aldehyde; RA, rheumatoid arthritis; TGF $\beta 1$, transforming growth factor $\beta 1$; TUNEL, terminal deoxy (d)-UTP nick end labelling 


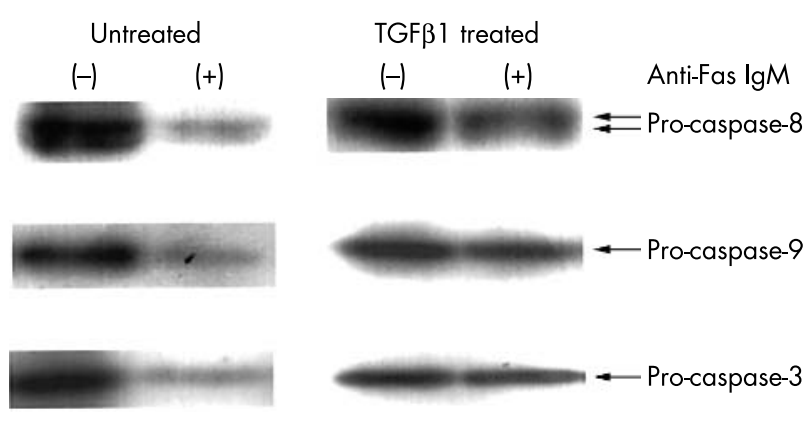

Figure 1 Western blot analysis for the activation of caspase-3/-8/-9 in synovial cells induced by anti-Fas $\lg M$, which is inhibited by TGF $\beta 1$. Synovial cells isolated from the rheumatoid synovial tissues were cultured with or without TGF $\beta 1$ for 48 hours, washed, and further incubated with control mouse IgM or anti-Fas IgM for 12 hours. After cultivation, the expression of procaspase-3/-8/-9 in synovial cells was examined by western blotting as described in the text. Note that the disappearance of procaspase-3/-8/-9 in anti-Fas IgM treated synovial cells, which indicates the activation of each caspase, was significantly inhibited by TGF $\beta 1$ treatment. Results are representative data from six determinations. anti-Fas IgM (-); addition of control mouse lgM.

enhanced chemiluminescence system (Amersham, Arlington Heights, IL, anti-caspase-3; Transduction Laboratories, Lexington, KY, anti-caspase-8; MBL, anti-caspase-9; MBL). Decrement of procaspase expression and/or the appearance of cleaved products indicate the activation of each caspase. ${ }^{10}$ In addition to western blotting, increment of an enzymatic activity of Asp-Glu-Val-Asp ase (DEVDase: caspase-3 like activity), Ile-Glu-Thr-Asp ase (IETDase: caspase-8 like activity), and Leu-Glu-His-Asp ase (LEHDase: caspase-9 like activity) was used for detection of activation in each caspase.

Enzymatic activity of DEVDase (intracellular DEVDase ${ }^{+}$ cells) was detected by flow cytometry (Epics XL) by the use of DEVD substrate (OncoImmunin, Inc, College Park, MD) as previously described. ${ }^{8}$ Enzymatic activity of both IETDase and LEHDase was examined by colorimetric protease assay kit (MBL), and the activity of IETDase and LEHDase was evaluated by a spectrophotometer at an optical density of $405 \mathrm{~nm}$ (Multiskan JX, LABSYSTEMS, Tokyo, Japan), according to the manufacturer's protocol.

Expression of Bcl-2 (anti-Bcl-2; Dako Japan, Kyoto, Japan), Bcl-xL (anti-Bcl-xL; Trevigen, Gaithersburg, CA), and Bax (anti-Bax; Santa Cruz Biotechnology, Santa Cruz, CA) in synovial cells was studied by western blotting, and a relative expression ratio of Bcl-2 to Bax and of Bcl-xL to Bax was calculated by the software NIH Image (1.61) as follows: density of Bcl-2 or Bcl-xL/density of $\beta$-actin to density of Bax/ density of $\beta$-actin. $\beta$-Actin (anti- $\beta$-actin; Sigma) was used as an internal control protein in western blotting.

Mitochondrial perturbation in synovial cells was examined by $\Delta \Psi \mathrm{m} .^{9}$ The cells were reacted with saturating amount of DiOC6 (3,3'-dihexyloxacarbocyamine iodide, Fluoreszenztechnologie, Grottenhofstr, Austria) at $37^{\circ} \mathrm{C}$ for 15 minutes, washed, and analysed by flow cytometry. In some experiments, synovial cells were cultured in the presence of Z-Val-Ala-Asp- $\mathrm{CH}_{2} \mathrm{DCB}$ (caspase inhibitor, $200 \mu \mathrm{M}$; Phoenix Pharmaceuticals, Inc, Mountain View, CA), and apoptosis of these cells was also examined.

\section{Statistical analysis}

Data were expressed as mean (SD). Differences between groups were tested for statistical significance using the Student's $t$-test. A p value $<0.05$ was considered significant.

\section{RESULTS}

\section{Inhibition of Fas mediated mitochondrial perturbation} in cultured synovial cells by TGF $\beta 1$

Although we did not find the cleaved products of each caspase, activation of caspase-3/-8/-9 in synovial cells by antiFas IgM was strongly suggested by western blotting (fig 1), which was confirmed by an enzymatic activity assay for DEVDase, IETDase, and LEHDase (table 1). Mitochondrial perturbation with DNA fragmentation in synovial cells was also clearly induced by anti-Fas IgM (table 1). Expression of procaspase-3/-8/-9 in synovial cells was not changed by TGF $\beta 1$ (fig 1), but TGF $\beta 1$ treatment significantly suppressed $\Delta \Psi \mathrm{m}$, activation of caspase-3/-8/-9, and DNA fragmentation of synovial cells induced by anti-Fas IgM (fig 1, table 1).

\section{Effect of TGF 1 for synovial cell apoptosis induced by other apoptogenic stimuli}

We next examined whether TGF $\beta 1$ treatment protects mitochondrial perturbation induced by other apoptogenic stimuli. LLL-CHO, etoposide, and C2-ceramide, the chemicals triggering apoptosis in a mitochondria dependent fashion, ${ }^{11-13}$ induced $\Delta \Psi \mathrm{m}$ with the presence of DNA fragmentation toward synovial cells (table 2). Z-Val-Ala-Asp- $\mathrm{CH}_{2} \mathrm{DCB}$ did not inhibit $\Delta \Psi \mathrm{m}$ of synovial cells in the process (data not shown), which supported the importance of the mitochondrial pathway in synovial cell death induced by LLL-CHO, etoposide, and C2-ceramide. Activation of both LEHDase and DEVDase was also clearly found in synovial cells treated with the chemicals, and TGF $\beta 1$ treatment significantly suppressed the above hallmarks for apoptosis (table 2). As we previously described, ${ }^{3}$ the relative expression ratio of $\mathrm{Bcl}-2$ or $\mathrm{Bcl}-\mathrm{xL}$ to Bax in synovial cells was increased by TGF $\beta 1$ (untreated synovial cells: Bcl-2 to Bax 0.56 (0.05) and Bcl-xL to Bax; 0.12 (0.01); TGF $\beta 1$ treated synovial cells: Bcl-2 to Bax $0.95(0.07)^{*}$ and Bcl-xL to Bax $0.88(0.06)^{*} ;{ }^{*} \mathrm{p}<0.01 v$ untreated synovial

Table 1 Inhibition of Fas mediated apoptosis of synovial cells by TGF $\beta 1$

\begin{tabular}{|c|c|c|c|c|c|c|c|}
\hline \multicolumn{2}{|l|}{ Stimuli } & \multicolumn{6}{|l|}{ Apoptosis } \\
\hline Anti-Fas Ig $M$ & TGF $\beta 1$ & $\begin{array}{l}\text { Hypodiploid DNA } \\
\text { (\%) }\end{array}$ & $\begin{array}{l}\text { TUNEL } \\
(\%)\end{array}$ & $\begin{array}{l}\Delta \Psi \mathrm{m} \\
(\%)\end{array}$ & $\begin{array}{l}\text { DEVDase } \\
(\%)\end{array}$ & $\begin{array}{l}\text { IETDase } \\
\text { (OD) }\end{array}$ & $\begin{array}{l}\text { LEHDase } \\
\text { (OD) }\end{array}$ \\
\hline- & - & $1.4(0.1)$ & $2.1(0.1)$ & $1.0(0.1)$ & $1.6(0.1)$ & $0.32(0.03)$ & $0.34(0.09)$ \\
\hline - & + & $1.3(0.2)$ & $2.1(0.2)$ & $1.0(0.1)$ & $1.5(0.1)$ & $0.29(0.03)$ & $0.31(0.04)$ \\
\hline+ & - & $60.3(5.9)^{*}$ & $45.8(3.9)^{*}$ & $61.5(5.6)^{*}$ & $62.5(6.1)^{*}$ & $0.96(0.07)^{*}$ & $0.92(0.07)^{*}$ \\
\hline+ & + & $14.2(1.1)^{*}$ & $12.5(1.4)^{*}$ & $14.1(1.4)^{*}$ & $12.9(1.4)^{*}$ & $0.44(0.03)^{*}$ & $0.39(0.03)^{*}$ \\
\hline
\end{tabular}

Rheumatoid synovial cells were cultured with or without TGF $\beta 1$ for 48 hours, washed, and further incubated with anti-Fas lgM for 12 hours. After cultivation, the percentage of hypodiploid DNA ${ }^{+}$cells, percentage of TUNEL cells, $\triangle \Psi \mathrm{m}$, DEVDase activity, IETDase activity, and LEHDase activity were examined as described in the text. Note that apoptotic cell death of synovial cells induced by anti-Fas IgM was significantly suppressed by TGF $\beta 1$. Results are mean (SD) from six individual experiments.

Anti-Fas IgM (-): addition of control mouse IgM. OD of IETDase and LEHDase was described as OD/ $\mu$ g protein. ${ }^{*} \mathrm{p}<0.01$. 
Table 2 TGF $\beta 1$ mediated inhibition in synovial cell apoptosis induced by LLL-CHO, etoposide and C2-ceramide

\begin{tabular}{|c|c|c|c|c|c|c|}
\hline \multirow[b]{2}{*}{ Stimuli } & \multirow[b]{2}{*}{ TGF $\beta 1$} & \multicolumn{5}{|l|}{ Apoptosis } \\
\hline & & $\begin{array}{l}\text { Hypodiploid DNA } \\
\text { (\%) }\end{array}$ & $\begin{array}{l}\text { TUNEL } \\
\text { (\%) }\end{array}$ & $\begin{array}{l}\Delta \Psi \mathrm{m} \\
(\%)\end{array}$ & $\begin{array}{l}\text { DEVDase } \\
(\%)\end{array}$ & $\begin{array}{l}\text { LEHDase } \\
\text { (OD) }\end{array}$ \\
\hline \multirow[t]{2}{*}{ LLL-CHO } & - & $23.2(1.8)^{*}$ & $19.0(1.8)^{*}$ & $22.7(2.5)^{*}$ & $25.1(2.0)^{*}$ & $0.68(0.05)^{*}$ \\
\hline & + & $5.9(0.4)^{*}$ & $5.0(0.4)^{\star}$ & $5.7(0.8)^{*}$ & $6.8(0.8)^{*}$ & $0.39(0.03)^{*}$ \\
\hline \multirow{2}{*}{ Etoposide } & - & $20.1(2.2)^{*}$ & $18.2(1.7)^{*}$ & $19.6(1.7)^{*}$ & $19.7(1.9)^{*}$ & $0.69(0.06)^{*}$ \\
\hline & + & $5.1(0.5)^{*}$ & $5.2(0.4)^{*}$ & $5.2(0.7)^{*}$ & $5.7(0.6)^{*}$ & $0.43(0.04)^{*}$ \\
\hline \multirow{2}{*}{ C2-ceramide } & - & $22.5(1.5)^{\star}$ & $19.5(1.7)^{*}$ & $22.4(2.2)^{*}$ & $23.9(2.1)^{*}$ & $0.72(0.06)^{*}$ \\
\hline & + & $6.5(0.7)^{*}$ & $5.4(0.3)^{\star}$ & $6.3(0.7)^{*}$ & $6.5(0.7)^{*}$ & $0.42(0.04)^{*}$ \\
\hline
\end{tabular}

Rheumatoid synovial cells were cultured with or without TGF 1 for 48 hours, washed, and further incubated with LLL-CHO, etoposide, or C2-ceramide for 24 hours. After cultivation, the percentage of hypodiploid DNA ${ }^{+}$cells, percentage of TUNEL ${ }^{+}$cells, $\triangle \Psi \mathrm{m}, \mathrm{DEVDase}$ activity, and LEHDase activity were examined as described in the text. Note that apoptotic cell death of synovial cells induced by LLL-CHO, etoposide, and C2-ceramide was significantly suppressed by TGF $\beta 1$. Results are mean (SD) of five individual experiments.

$\mathrm{OD}$ of LEHDase was described as $\mathrm{OD} / \mu \mathrm{g}$ protein. Each parameter in untreated and TGF $\beta 1$ treated synovial cells cultured in the absence of LLL-CHO, etoposide, or C2-ceramide was the same as in table 1.

* $\mathrm{p}<0.01$.

cells. Results are the mean (SD) of five individual experiments. We found no difference in TGF $\beta 1$ induced inhibition for synovial cell apoptosis induced by anti-Fas IgM, LLL$\mathrm{CHO}$, etoposide, and $\mathrm{C} 2$-ceramide between rheumatoid synovial cells and synovial cells isolated from patients with osteoarthritis (data not shown).

\section{DISCUSSION}

Our series of studies have indicated that the growth promoting activity of TGF $\beta 1$ for synovial cells can, in part, be mediated by inhibition of synovial cell apoptosis. ${ }^{2}{ }^{3}$ As reported in other cell types, ${ }^{14}{ }^{15}$ activation of caspase-3/-8/-9 as well as $\Delta \Psi \mathrm{m}$ was found in anti-Fas monoclonal antibody treated synovial cells, whereas these hallmarks for apoptosis were markedly suppressed in TGF $\beta 1$ treated synovial cells.

Mitochondrial dysfunction in synovial cells was also induced by LLL-CHO, etoposide, and C2-ceramide, leading to the activation of caspase-3/-9 and DNA fragmentation. TGF $\beta 1$ treatment significantly suppressed apoptogenic activity of LLL-CHO, etoposide, and C2-ceramide. As we previously reported, ${ }^{3}$ relative expression of $\mathrm{Bcl}-2$ and $\mathrm{Bcl}-\mathrm{xL}$ was increased by TGF $\beta 1$, which may prevent the release of cytochrome $c$ and apoptotic cell death of synovial cells induced by the above chemicals. TGF $\beta 1$ mediated protection for the mitochondria may also be effective in Fas induced apoptosis in synovial cells.

Impaired apoptosis of synovial cells in rheumatoid synovial tissues is supposed to have an important role in the progression of synovial cell hyperplasia of patients with RA, but recent investigations have suggested its characteristic may not be an intrinsic property of rheumatoid synovial cells, but that the rheumatoid synovial microenviroment affects the sensitivity of synovial cell apoptosis. ${ }^{1-5}{ }^{12}$ One factor which may inhibit apoptosis of synovial cells is TGF $\beta 1$, but rheumatoid synovial tissue contains a variety of cytokines and growth factors other than TGF $\beta 1$, which also inhibit apoptotic cell death of synovial cells, including basic fibroblast growth factor and interleukin $1 \beta .{ }^{1{ }^{4}}$ The present data are obtained only under bovine serum albumin culture conditions, thus, the in vivo role of TGF $\beta 1$ in rheumatoid synovial tissues remains obscure. Further investigations, including interactions between TGF $\beta 1$ and other humoral factors, are necessary to clarify the in vivo role of TGF $\beta 1$ in the regulation of apoptotic cell death of synovial cells of patients with RA.

\section{ACKNOWLEDGEMENTS}

We thank Misses Yoko Uchiyama and Nobuko Fukuda for their technical assistance.

\section{Authors' affiliations}

A Kawakami, S Yamasaki, A Hida, T Miyashita, M Kamachi, K Nakashima, F Tanaka, H Ida, K Migita, K Eguchi, The First Department of Internal Medicine, Nagasaki University School of Medicine, 1-7-1 Sakamoto, Nagasaki 852-8501, Japan

T Origuchi, Department of Physical Therapy, Nagasaki University School of Medicine, 1-7-1 Sakamoto, Nagasaki 852-8501, Japan

S Urayama, Y Kawabe, Department of Internal Medicine, National Ureshino Hospital, Saga, Japan

T Aoyagi, I Furuichi, Department of Orthopaedics, National Ureshino Hospital, Saga, Japan

Correspondence to: Dr A Kawakami, The First Department of Internal Medicine, Nagasaki University School of Medicine, 1-7-1 Sakamoto, Nagasaki 852-8501, Japan; atsushik@net.nagasaki-u.ac.jp

Accepted 24 April 2003

\section{REFERENCES}

1 Kawakami A, Eguchi K. Involvement of apoptotic cell death in autoimmune diseases. Med Electron Microsc 2002;35:1-8.

2 Kawakami A, Eguchi K, Matsuoka N, Tsuboi M, Kawabe Y, Aoyagi T, et al. Inhibition of Fas antigen-mediated apoptosis of rheumatoid synovial cells in vitro by transforming growth factor $\beta 1$. Arthritis Rheum 1996;39:1267-76.

3 Kawakami A, Nakashima T, Sakai H, Hida A, Urayama S, Yamasaki S, et al. Regulation of synovial cell apoptosis by proteasome inhibitor. Arthritis Rheum 1999;42:2440-8

4 Tsuboi M, Eguchi K, Kawakami A, Matsuoka N, Kawabe Y, Aoyagi T, et al. Fas antigen expression on synovial cells was down-regulated by interleukin 13. Biophys Biochem Res Commun 1996:218:280-5

5 Yamasaki S, Kawakami A, Nakashima T, Nakamura H, Kamachi M, Honda S, et al. Importance of NF- $\kappa B$ in rheumatoid synovial tissues: in situ NF- $\kappa B$ expression and in vitro study using cultured synovial cells. Ann Rheum Dis 2001;60:678-84.

6 Arend WP, Dayer J-M. Cytokines and cytokine inhibitors or antagonists in rheumatoid arthritis. Arthritis Rheum 1990;33:305-15.

7 Arnett FC, Edworthy SM, Bloch DA, McShane DJ, Fries JF, Cooper NS, et al. The American Rheumatism Association 1987 revised criteria for the classification of rheumatoid arthritis. Arthritis Rheum 1988:31:315-24.

8 Hida A, Kawakami A, Nakashima T, Yamasaki S, Sakai H, Urayama S, et al. Nuclear factor-kappaB and caspases co-operatively regulate the activation and apoptosis of human macrophages. Immunology 2000;99:553-60.

9 Shibatomi K, Ida H, Yamasaki S, Nakashima T, Origuchi T, Kawakami A et al. A novel role interleukin-18 in human NK cell death: high serum levels and low NK cell number in systemic autoimmune diseases. Arthritis Rheum 2001;44:884-92.

10 Green DR. Apoptotic pathways: the roads to ruin. Cell 1998;94:695-8.

11 Kroemer G, Reed JC. Mitochondrial control of cell death. Nature Med 2000;6:513-19.

12 Perlman H, Georganas C, Pagliari U, Koch AE, Haines K K III, Pope RM. Bcl-2 expression in synovial fibroblasts is essential for maintaining mitochondrial homeostasis and cell viability. J Immunol 2000;164:5227-35.

13 Wagenknecht B, Hermisson M, Groscurth P, Liston P, Krammer PH, Weller M. Proteasome inhibitor-induced apoptosis of glioma cells involves the processing of multiple caspases and cytochrome c release. J Neurochem 2000;75:2288-97.

14 Scaffidi C, Schmitz I, Zha J, Korsmeyer SJ, Krammer PH, Peter ME. Differential modulation of apoptosis sensitivity in CD95 type I and type II cells. J Biol Chem 1999;274:22532-8.

15 Gewies A, Rokhiin OW, Cohen MB. Cytochrome c is involved in Fas-mediated apoptosis of prostatic carcinoma cell lines. Cancer Res 2000;60:2163-8. 